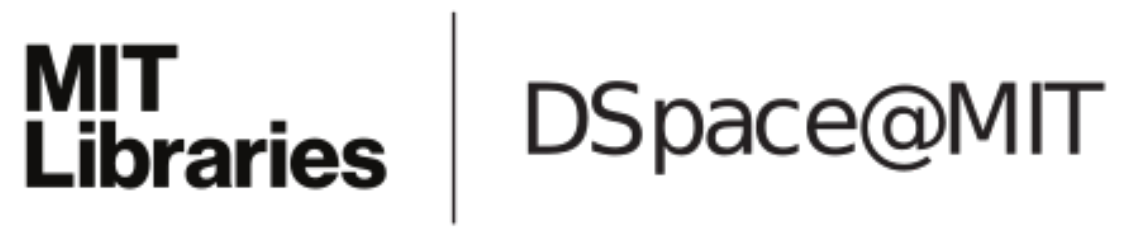

\author{
MIT Open Access Articles
}

Empirical Shipment Size Model for Urban Freight and its Implications

The MIT Faculty has made this article openly available. Please share how this access benefits you. Your story matters.

Citation: Sakai, Takanori, et al. "Empirical Shipment Size Model for Urban Freight and Its Implications." Transportation Research Record, vol. 2674, no. 5, May 2020, pp. 12-21,

As Published: $10.1177 / 0361198120914890$

Publisher: SAGE Publications

Persistent URL: https://hdl.handle.net/1721.1/132688

Version: Author's final manuscript: final author's manuscript post peer review, without publisher's formatting or copy editing

Terms of use: Creative Commons Attribution-Noncommercial-Share Alike 


\section{An Empirical Shipment Size Model for Urban Freight and Its Implications}

\section{Takanori Sakai}

Singapore-MIT Alliance for Research and Technology (SMART)

1 CREATE Way, \#09-02 CREATE Tower, Singapore 138602

Tel: +65-6601-1636

Email: takanori@smart.mit.edu

\section{André Alho}

Singapore-MIT Alliance for Research and Technology (SMART)

1 CREATE Way, \#09-02 CREATE Tower, Singapore 138602

Tel: +65-6601-1636

Email: andre.romano@smart.mit.edu

\section{Tetsuro Hyodo}

Department of Logistics and Information Engineering

Tokyo University of Marine Science and Technology

2-1-6, Etchujima Koto-ku, Tokyo, Japan 135-8533

Tel: +81-3-5245-7386

Email: hyodo@kaiyodai.ac.jp

\section{Moshe Ben-Akiva}

Intelligent Transportation Systems Lab

77 Massachusetts Avenue, Room 1-181

Cambridge, M.A., 02139, U.S.A.

Tel: 617-253-5324

Email:mba@mit.edu

Word Count: 4663 words +5 tables $=5,913$ words

\section{FUNDING}

The author(s) disclosed receipt of the following financial support for the research, authorship, and/or publication of this article: This research is supported in part by the Singapore Ministry of National Development and the National Research Foundation, Prime Minister's Office under the Land and Liveability National Innovation Challenge (L2 NIC) Research Programme [L2 NIC Award No L2 NICTDF1-2016-1]. Any opinions, findings, and conclusions or recommendations expressed in this material are those of the author(s) and do not reflect the views of the Singapore Ministry of National Development and National Research Foundation, Prime Minister's Office, Singapore.

\section{DATA ACCESSIBILITY}

The authors do not have permission to share data. 


\begin{abstract}
Shipment size modeling for intra-city shipments is one of the subjects which have not been sufficiently addressed in past research, despite its growing importance in disaggregate freight modeling. While the past research on shipment size estimation mainly focuses on inter-city shipments, intra-city shipments are different from the inter-city shipments in various aspects. For filling this research gap, we estimate shipment size models using the records of intra-city shipments, identifying the effects of factors and the heterogeneity on the shipment size selection mechanism. We also compare the estimated coefficients against their theoretical values derived from a conceptual Economic Order Quantity model. The estimated empirical models highlight the characteristics of intra-city shipments and indicates the importance of both receiver function and commodity type, and also vehicle operation type, in capturing the nuances of the selection mechanism among intra-city shipments.
\end{abstract}

Keywords: Shipment Size, Freight Modeling, Urban Freight, City Logistics 


\section{INTRODUCTION}

Understanding and replicating agent behaviors related to urban freight is recognized as an important research topic along with the growing concern about the impact of freight vehicles on urban mobility and sustainability, as well as the interests of planners on urban freight management (1). Existing literature that analyzes and/or models shipment sizes focuses on inter-city (or interregional) shipments. On the other hand, shipment size modeling in the urban freight context has not been addressed to the extent that meets its importance. Shipment size modeling often relies on the concept of the Economic Order Quantity (EOQ) model, which provides a theoretical basis for the relationship between the optimum shipment size and the unit costs of ordering, transporting, and inventory $(2,3,4)$. However, a conceptual EOQ model with theoretical coefficient values may not be applicable for intra-city (or intra-metropolitan) shipments due to their characteristics, which are different from inter-city shipments in various ways. Transport cost structure for intra-city shipments is, in general, more complex due to the greater potential for multiple-delivery/pickup tours, the more dynamic and unpredictable urban traffic conditions, and the higher costs for delivery/pickup parking. Furthermore, the inventory capacities of intra-city-shipment receivers are often low, especially those of small offices and stores, (at least, partially) due to their high shadow prices of inventory. Moreover, the characteristics of intra-city-shipment receivers (e.g. function type), generally speaking, are more diverse than those of inter-city shipments. All these features underline the need for the detailed analysis of the shipment size selection mechanism for intra-city shipments.

In this paper, "shipment" is defined as goods, or a bundle of goods, that is transported together at the same time between a shipper and a receiver (5). While in some studies of interregional shipments, a shipment is assumed consisting of a sequence of legs that connect the first origin, intermediate facilities, and the last destination, we consider a goods movement that is destined to and/or originated from an intermediate facility is also a "shipment". Furthermore, we consider that each shipment can be associated with a commodity flow contract (hereafter called simply "contract"). We define a contract as a specification of the total commodity flow (in weight) between a supplier and a receiver per time period. The focus of our research is business-to-business shipments.

We estimate a set of models for unveiling how the above-mentioned features of intra-city shipments play a role in shipment size selection. Our modeling approach considers the nuances in the shipment size choice mechanism attributable to both commodity and receiver function type, which have not been addressed by the past research. The analysis is especially important for understanding the link between the commodity flow and shipment frequency, which has significant impact on associated urban freight traffic. While the estimated models are integrated to an agentbased urban freight simulating system, named SimMobility Freight ( 6 ), the main objective of this research is not to propose "better" predictive models but to understand the shipment size selection mechanism for intra-city shipments in depth.

The rest of the paper is organized as follows; a literature review that focuses on shipment size estimation, a description of the conceptual model for intra-city shipment sizes; the data and empirical model formulation; the result of empirical model estimation; and the conclusions drawn from the research.

\section{LITERATURE REVIEW}

The conversion from commodity flow to vehicle flow is an important step in commodity-based freight modeling. Conventional models use constant load factors for converting commodity flow to truck trips for simplification, dismissing the decision mechanism for shipment size as well as 
vehicle loading. Even urban freight models that were recently introduced omit or simplify such mechanism. Moeckel and Donnelly (7) use load factors in their model for Chicago Metropolitan Area and Nuzzolo and Comi (8) use average shipment sizes defined for four transport service types.

The importance of shipment size estimation is, on the other hand, recognized for freight models that focus on the logistics decisions in a disaggregate manner. The shipment size model used in an urban freight simulator developed by Wisetjindawat and Sano (9), called "ordering frequency model", is a simplified EOQ model that depends only on the quantity of commodity flow and trip distance. Wisetjindawat et al. (10) introduce another version which further considers industry type, i.e. warehouse, manufacturer, or retailer. These models do not consider commodity type and assume that storage cost (called "holding cost") is constant across all receivers. In a conceptual framework for urban freight modeling proposed by Roorda et al. (11), shipment size (called "order quantity") is treated as the function of demand size, ordering cost, and carrying cost but storage cost is not included. In a national-scale model, Liedtke (12) uses the theoretical total logistics cost including storage, ordering and handling costs, and transport rate, for its heuristic optimization module to determine shipment size. For a spatial scale greater than a city, a number of articles propose joint models for mode choice and shipment or vehicle size. The underlying hypothesis is that the choice of shipment size is not independent from that of transport mode/truck size. For example, Abate and de Jong (3) estimate a discrete-continuous model of shipment size and vehicle-size class, using the data from the Danish heavy trucks trip diary in 2006/2007, a national scale survey data. A two-steps estimation method is used to remove the simultaneity bias that occurs in the decisions of shipment and vehicle sizes. Abate et al. (13) propose a discretediscrete model for transport mode chain and shipment size as a part of the national freight transport model for Sweden. Similarly, Stinson et al. (14) estimate a nested logit model for transport mode (defined as the first level) and discretized shipment size (defined as the second level) using the records from US Commodity Flow Survey Microdata. Pourabdollahi et al. (15) propose a copulabased joint model for freight mode and shipment size. The list of the studies which focus on modeling approach for similar joint decisions is provided by Irannezhad et al. (16); none of those studies exclusively focus on intra-city shipments.

Irannezhad et al. (16) estimate a joint model for shipment size and vehicle type choice using the data that covers a considerable number of intra-city shipments in Mashhad, Iran. While their main research focus is model formulation, the result from the model estimation is insightful, indicating the existence of the relationships between delivery time and shipment size and between vehicle size and shipment characteristics as well as the difference in the choice mechanism between shippers and carriers. However, their model does not consider the information of receivers, who are the key stakeholders on shipment size selection, such as inventory costs at receivers, which presumed highly important for intra-city shipments.

Many modeling studies use an EOQ model as the theoretical basis for selecting the independent variables $(3,4,9,17,18,19)$ although the variables which are actually used in model estimation vary depending on data availability. Combes (2) assesses the validity of a conceptual EOQ model with theoretical coefficient values by comparing it with an empirical shipment size model estimated using domestic shipment records from the French ECHO database. The analysis confirms that the estimated coefficients of total commodity flow and the value of goods roughly match with their theoretical values. He also confirms that shipment size depends on vehicle operation type, i.e. full-truckload, less-than-truckload, or multiple deliveries/pickups. 
As discussed above, the existing research of shipment size mainly focuses on the areas that are larger than a city. Some urban freight models cover a shipment size model but receiver-side information, which we hypothesize as key factors on shipment size choice for intra-city shipments, are not considered. Shipments to two different locations, one in a business district in the city center and another in a suburb, should have different sizes as inventory costs (i.e. storage cost) in those locations are different. This research attempts to fill such research gap. We estimate shipment size models considering receiver information for intra-city shipments using the data from a large metropolitan area. We also examine if a conceptual EOQ model with theoretical coefficient values is directly applicable for intra-city shipments like Combes (2) did with the national shipment records.

\section{BENCHMARK CONCEPTUAL MODEL FOR INTRA-CITY SHIPMENT SIZE}

As discussed in literature review, the EOQ model is widely used because of its solid theoretical basis that relies on the assumption of cost minimization. In this section, we derive a theoretical formulation for an intra-city shipment size model, following the typical approach to derive a conceptual EOQ model. We assume the total logistics cost (TLC) for a contract $i$ is the sum of three different cost components, namely:

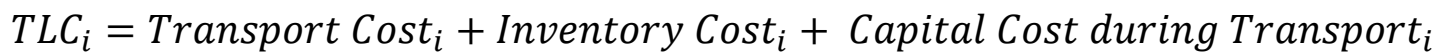

Transport cost and inventory cost at the receiver for contract $i$ are assumed as follows:

Transport Cost $_{i}=Q_{i} / q_{i} \cdot o_{i}\left(q_{i}, d_{i}\right)$

$o_{i}\left(q_{i}, d_{i}\right)=\left(\beta_{1}+\beta_{2} \cdot q_{i}\right) \cdot d_{i}$

Inventory Cost at the Receiver ${ }_{i}=q_{i} / 2 \cdot w_{i}$

where $Q_{i}$ is the size of contract; $q_{i}$ is the shipment size; $d_{i}$ is the shipment distance; $o_{i}\left(q_{i}, d_{i}\right)$ is the transport cost per shipment; and $w_{i}$ is the storage cost per unit.

Transport cost is the product of the shipment frequency and the per-shipment unit cost (Eq. (2)). The per-shipment unit cost is defined as the function of the shipment size (in terms of weight) and the shipment distance. $\beta_{1}$ and $\beta_{2}$ in Eq. (3) should differ by commodity as the transport cost of some commodity is potentially more sensitive to the size than that of another commodity. The inventory cost at the receiver is defined as Eq. (4), following the typical practice for the derivation of the EOQ model. $q_{i} / 2$ is the average level of inventory.

Assuming shippers for intra-city shipments often handle high frequency shipments for a large number of different contracts, the marginal effect of a shipment size for a single contract on the shipper's inventory cost can be negligible. Thus, the inventory cost at the shipper side is assumed independent from the shipment size for a single contract. Furthermore, the capital cost during transport is the product of total commodity flow, interest rate, value of goods, and travel time, and therefore, independent from the shipment size. Thus, Eq. (1) can be rewritten as:

$T L C_{i}=Q_{i} / q_{i} \cdot\left(\beta_{1}+\beta_{2} \cdot q_{i}\right) \cdot d_{i}+q_{i} / 2 \cdot w_{i}+$ other costs independent from $q_{i}$

Minimizing TLC in Eq. (5) with respect to $q_{i}$ results in: 
$q_{i}=\sqrt{2 \cdot Q_{i} \cdot \beta_{1} \cdot d_{i} / w_{i}}$

$\ln q_{i}=1 / 2 \ln Q_{i}+1 / 2 \ln d_{i}-1 / 2 \ln w_{i}+1 / 2 \ln 2 \beta_{1}$

Eq. (7) is a theoretical formulation of shipment size (i.e. a conceptual EOQ model with theoretical coefficient values). We will use this equation as a benchmark for comparison with empirical models which we estimate.

\section{DATA AND MODEL}

\section{Data}

For the empirical model estimation, we use the shipment records collected by 2013 Tokyo Metropolitan Freight Survey (TMFS). The TMFS is an establishment survey that targets the establishments that are engaged in freight activities in the Tokyo Metropolitan Area (TMA). The TMA has a typical monocentric urban system with the highest population and business densities around its center (Figure 1). Information about the establishments and their outbound and inbound shipment records were collected in the survey. 20,583 inbound shipment records by 3,961 establishments are used for the model estimation. These shipment records are detailed by eight commodity and four receiver function types (office, factory, shop \& restaurant, and logistics facility) in Table 1 . The records of shipments to office and shop \& restaurant are relatively small as the TMFS was designed to target the freight-activity intensive facilities (i.e., factories and logistics facilities). However, this bias in the samples is not a concern for model estimation, as a model is estimated for each commodity type - receiver function combination as described in the following subsection.

The mean shipment size, together with the standard deviation (SD) in parentheses, is shown in Table 2 for each commodity-receiver function combination. The SDs are higher than the means for all combinations because the distributions of shipment sizes are positively skewed to a significant degree. Table 2 also shows the results of the statistical tests, one-way ANOVA and Kruskal-Wallis test, which compare the mean shipment sizes across different receiver functions. Both tests indicate statistically significant differences in the mean shipment size among receiver function types for all eight commodity types.

The summary statistics of independent variables is shown in Table 3 . As the exact contract sizes associated with shipment records are not available from the TMFS, we use estimated values. We compute the average contract size for intra-city shipments based on the total inbound flow, the number of suppliers, and the share of intra-city shipments, all of which are available at the establishment level. The average contract size of each receiver-establishment is used as the size of the contracts associated with the establishment. The exact geographical locations of shipment receivers are available, as well as shippers' locations at the municipality level. We use those data to calculate shipment distance, which is the length $(\mathrm{km})$ of the network-based shortest path between the shipper and the receiver, and the land price at the receiver's location (i.e. a $1 \mathrm{~km}$-by$1 \mathrm{~km}$ polygon where the receiver is located). The land price data, which is originally from the pubic archives of Government of Japan, was provided by the Tokyo Planning Commission of the Tokyo Metropolitan Region (TPCTMR). 


\section{Specification for empirical model}

The shipment size selection for intra-city shipments is expected to highly depend on receiver's characteristics, especially facility function type. Unlike inter-city shipments, for which facility function types of shippers and receivers are predominantly factories and logistics facilities (e.g. warehouses and distributions centers), a considerable share of intra-city shipments are sent to retail shops, restaurants, and offices. Those different facility functions should have different inventory management strategies. Furthermore, the mechanism for the shipment size selection should also be different by commodity type. We segment the shipment records by commodity type and receiver function type to analyze the differences in the shipment size decision-making mechanism.

The model is specified as a linear model with the log-transformed shipment size as the dependent variable. The log of shipment size for the contract $i$ of a receiver $n$ of function type $f$ for commodity type $c$ is given by the following equation.

$$
\begin{aligned}
& \text { ln } s_{i^{n}}=\beta_{\text {const. }}^{c, f}+\beta_{\text {lfship }}^{c, f} \cdot d u m_{l f \text { ship }_{i}{ }^{n}}+\beta_{c_{-} \text {size }}^{c, f} \cdot \ln c_{-} \text {size }_{i^{n}} \\
& +\beta_{\text {dist. }^{c, f}} \cdot \text { ln dist. }_{\cdot{ }^{n}}+\beta_{\text {lfship_dist. }^{c, f}} \cdot \text { dum }_{\text {lfship }_{i^{n}}} \cdot \ln \text { dist. }_{\cdot{ }^{n}}+\beta_{L P}^{c, f} \cdot \ln L P_{n}
\end{aligned}
$$

where $c_{-}$size $_{i^{n}}$ is the contract size in terms of weight (metric ton per annual); dum $_{l f \text { ship }_{i^{n}}}$ is a dummy variable, which is 1 if the shipper is a logistics facility and 0 otherwise; dist. ${ }^{n}{ }^{n}$ is the distance between the supplier and the receiver $(\mathrm{km}) ; L P_{\mathrm{n}}$ is the land price at the receiver's location (mil. JPY per $\mathrm{m}^{2}$ ); and $\beta_{\text {const. }}^{c, f}, \beta_{\text {lfship }}^{c, f}, \beta_{c_{-} \text {size }}^{c, f}, \beta_{\text {dist. }}^{c, f}, \beta_{\text {lfship_dist. }}^{c, f}$, and $\beta_{L P}^{c, f}$ are the parameters to be estimated.

$\beta_{c_{-} \text {size }}^{c, f}, \beta_{\text {dist. }}^{c, f}\left(\right.$ or $\beta_{\text {dist. }}^{c, f}+\beta_{\text {lfship_dist. }}^{c, f}$ in case the shipper is a logistics facility), and $\beta_{L P}^{c, f}$ are equivalent to the elasticities of the shipment size with respect to contract size, shipment distance and land price, respectively. $c_{-}$size $_{i^{n}}$ is known as a key determinant of the shipment size (2). A higher coefficient of $c_{-}$size ${ }_{i}{ }^{n}$ indicates that the change in commodity flow is more catered by the change in shipment size and less by the change in shipment frequency. If the shipment size follows the theoretical formulation (Eq. (7)), its coefficient, $\beta_{c_{-} \text {size }}^{c, f}$, must be around 0.5. Another variable, dist $_{\cdot i^{n}}$, is relevant to transport cost and, if the transport cost increases with shipment distance, the coefficient shows positive sign. The interaction of $d_{i s t} .^{n}{ }^{n}$ and $d u m_{l f \operatorname{ship}_{i^{n}}{ }^{n}}$ is also considered, assuming the shipments from logistics facilities would be more likely treated by multiple-delivery tours, which results in a different transport cost structure from the other shipments. It should be noted that, while not available for this analysis, it must be ideal to consider the variables that directly characterize the transport mode such as full-truckload, less-than truckload or parcel shipping (2). $L P_{\mathrm{n}}$ is a proxy of inventory cost on the receiver side (i.e. $w_{i}$ in Eq. (7)), for which the coefficient is expected to be negative. During the process of the analysis, we have also tested other variables such as travel time (as a variable related to travel cost), and population and employment densities at the receiver's location (as a proxy of inventory cost). These variables are not included in the final models since those included in the Eq. (8) give better model fits and provide reasonable coefficient estimates. It should be noted that the land price is not considered for the shipments shipped to logistics facilities, which are, in nature, the intermediate locations. The variable is not appropriate as a proxy of the inventory cost for this specific facility type since the land price correlates with the accessibility to the destinations of subsequent shipments from logistics facilities. Furthermore, when a supply chain is driven by demand-side (i.e. pull-logistics) and travel 
time is short and predictable, an operator of the facility simply tries to minimize handling time in a logistics facility regardless of shipment size. We use the least squares method to estimate coefficients.

\section{RESULTS}

\section{Estimated Empirical Models}

Table 4 and Table 5 shows the results of the model estimation. Generally speaking, the model fits tend to be higher for shipments to offices or shops/restaurants than those to factories or logistics facilities. The models for food and wood and paper products to logistics facilities have the lowest adjusted $\mathrm{R}^{2}, 0.29$ and 0.30 respectively, highlighting the non-homogeneous nature of those shipment types. In contrast, the models for agricultural and food products to offices and shops/restaurants shows very high $\mathrm{R}^{2}$ in the range between $0.78-0.81$, implying their homogeneity in shipment size decision mechanism within the commodity-receiver type categories.

The estimated coefficients indicate the heterogeneity of the effects of considered variables by receiver function and commodity type; especially, the difference by receiver function type is noteworthy. First of all, the constants $\left(\beta_{\text {const. }}^{c, f}\right)$ for all commodity types indicate that the sizes of shipments to logistics facilities tend to be much larger than the shipments to other facility types when the values of all three independent variables are the same. On the other hand, the shipments to offices and shops \& restaurants are relatively small, seemingly due to the nature of the commodities shipped to these facilities (e.g. finished products with small size packages). Subtle differences in the commodities would not be captured by the eight commodity types used for the analysis. In case the shipments to those facilities are from logistics facilities, the shipment size tends to be larger, especially the shipments to offices.

Second, the coefficients of the contract size are significant with the $95 \%$ confidence interval for all cases. Those for factories (as receivers) are around 0.52-0.61, which is consistent with the value of the EOQ model shown in Eq. (7) (i.e. 0.5), indicating that the theoretical coefficient is applicable to the shipments to factories. On the other hand, the coefficients of shop $\&$ restaurant are quite high: 0.74 when all commodity types are included, and greater than 0.8 for agricultural, food, and light manufacturing products. This indicates that the increase in shipment size is almost proportional to that in contract size. The result suggests that, for some products, such as food products received at shops \& restaurants, the frequency of the delivery tends to be fixed and, therefore, the increase in the demand (i.e. contract size) is catered by the increase in the shipment size.

Third, as for the effect of the distance, most of the estimated coefficients are significant with positive signs while there are some exceptions. The distance plays a relatively greater role in the sizes of the shipments to factories. This is understandable as the shipments to the factories are often full-truckload, and a large portion of transport cost can be explained by the shipment distance. As for the commodity type, agricultural products show greater coefficient values than the other commodity types; again, it is likely due to the full-truckload shipping for this commodity type. The effect of the distance is reduced when the shipments are from logistics facilities. Such effects are observed especially when the receivers are offices or shops \& restaurants. Together with the effects of dum $_{\text {lfship }}$, which are often positive to those receivers, this suggests that transport cost for the shipments from logistics facilities is less distance-dependent but more frequency-dependent. The combined effect of ln dist. and $d u m_{\text {lfship }} \cdot$ ln dist. shows even positive signs for some commodities (food and wood and paper products) sent from logistics 
facilities to offices. It seems that, in some cases, a large spatial service coverage for deliveries enables further consolidation of small shipments, which results in a cheaper cost for a longer distance shipment. Only for the shipments of light manufacturing goods to shops \& restaurants, the effect of distance is significantly negative when they are from non-logistics facilities. A close look at the samples indicates that this is caused by the records of shipments from offices or shops \& restaurants to shops \& restaurants; a number of very small shipments (typically, less than $5 \mathrm{~kg}$ ) sent from distant locations results in this seemingly contradicting effect. The above results underline the complexity of transport cost structure for intra-city shipments and indicate that whether shipments are moved in full truckload or less-than truckload needs to be predicted simultaneously, akin to a shipment size - mode choice model for inter-city shipments.

Lastly, a large share of the estimated coefficients of land price are significant with the expected sign (negative). The effects of the land price are especially remarkable when the receivers are offices. Storing is not the main function of this facility type and therefore its shadow price of storage must be high.

\section{CONCLUSIONS}

This research addresses a research gap related to shipment size modeling for intra-city shipments. We estimate the models using the shipment data from the Tokyo Metropolitan Area for different commodity type-receiver type combinations and discuss the estimated modes, comparing them to the benchmark conceptual EOQ model.

Combes (2) validates the use of conceptual EOQ model for shipments at the national level. However, our analysis indicates that it is inappropriate to use a conceptual model, instead of empirical models, for urban freight traffic estimation, due to the over-simplification of the logistics cost structure. We argue that, for making an EOQ model applicable, rather complex (and heterogeneous) cost structures should be reflected in the formulation. Further, it may even require the formulation from the perspective of profit maximization, instead of the minimization of the total logistics cost, as logistics decisions nowadays are driven by such broader perspective. For example, Hesse and Rodrigue (20) argue that logistics should be viewed as the integrated transport demand driven by the reciprocal relationship between the induced and derived demand functions.

The model fit varies across different categories, reflecting the homogeneity/heterogeneity in shipment size decision mechanism within those categories. The model coefficients obtained from the analysis indicate the importance of considering both receiver function and commodity types to capture the heterogeneity in the shipment size selection mechanism. Furthermore, the consideration of the shipper function (i.e. logistics facility/non-logistics facility) allows for taking into account the differences in transport cost structure. Ideally, vehicle operation type (e.g. vehicle tour type and full truckload/less-than truckload shipping), rather than shipper function type, should be considered for estimating a model. Our analysis implies that shipment size and vehicle operation are highly likely simultaneous decisions. The development of the joint model for shipment size vehicle operation decisions is an important future research task. For the development of such sophisticated model, it is critical to explore methods for collecting shipment-level data with details such as time of delivery, type of tour for the delivery, and traffic condition over a day. It is also worth mentioning that the logistics operations have been evolving over the decades and the future follow-up research that track their influences on the shipment size mechanism will be important. 


\section{ACKNOWLEDGEMENTS}

We thank the Urban Redevelopment Authority of Singapore, JTC Corporation and Land Transport Authority of Singapore for their support. We also thank the Transportation Planning Commission of the Tokyo Metropolitan Region for sharing the data for this research.

\section{AUTHOR CONTRIBUTIONS}

The authors confirm contribution to the paper as follows: study conception and design: T. Sakai, A. Alho, M. Ben-Akiva; data collection: T. Hyodo; analysis and interpretation of results: T. Sakai; draft manuscript preparation: T. Sakai, A. Alho. All authors reviewed the results and approved the final version of the manuscript. The authors do not have any conflicts of interest to declare.

\section{REFERENCES}

(1) Dablanc L, Giuliano G, Holliday K, O'Brien T. Best practices in urban freight management: Lessons from an international survey. Transportation Research Record. 2013;2379(1):29-38.

(2) Combes F. Empirical evaluation of economic order quantity model for choice of shipment size in freight transport. Transportation Research Record. 2012;2269(1):92-98.

(3) Abate M, De Jong G. The optimal shipment size and truck size choice-The allocation of trucks across hauls. Transportation Research Part A: Policy and Practice. 2014;59:262-277.

(4) Piendl R, Liedtke G, Matteis T. A logit model for shipment size choice with latent classesEmpirical findings for Germany. Transportation Research Part A: Policy and Practice. 2017;102:188-201.

(5) de Bok M, Tavasszy L. An empirical agent-based simulation system for urban goods transport (MASS-GT). Procedia Computer Science. 2018;130:126-133.

(6) Alho A, Bhavathrathan BK, Stinson M, Gopalakrishnan R, Le DT, Ben-Akiva M. A multiscale agent-based modelling framework for urban freight distribution. Transportation Research Procedia. 2017;27:188-196.

(7) Moeckel R, Donnelly R. A model for national freight flows, distribution centers, empty trucks and urban truck movements. Transportation Planning and Technology. 2016;39(7):693-711.

(8) Nuzzolo A, Comi A. Urban freight demand forecasting: a mixed quantity/delivery/vehiclebased model. Transportation Research Part E: Logistics and Transportation Review. 2014;65:84-98.

(9) Wisetjindawat W, Sano K. A behavioral modeling in micro-simulation for urban freight transportation. Journal of the Eastern Asia Society for Transportation Studies. 2003;5(3):2193-2208.

(10) Wisetjindawat W, Sano K, Matsumoto S. Supply chain simulation for modeling the interactions in freight movement. Journal of the Eastern Asia Society for Transportation Studies. 2005;6:2991-3004.

(11) Roorda MJ, Cavalcante R, McCabe S, Kwan H. A conceptual framework for agent-based modelling of logistics services. Transportation Research Part E: Logistics and Transportation Review. 2010;46(1):18-31.

(12) Liedtke G. Principles of micro-behavior commodity transport modeling. Transportation Research Part E: Logistics and Transportation Review. 2009;45(5):795-809.

(13) Abate M, Vierth I, Karlsson R, de Jong G, Baak J. A disaggregate stochastic freight transport model for Sweden. Transportation. 2019;46(3):671-696.

(14) Stinson M, Pourabdollahi Z, Livshits V, Jeon K, Nippani S, Zhu H. A joint model of mode and shipment size choice using the first generation of Commodity Flow Survey Public Use 
Microdata. International Journal of Transportation Science and Technology. 2017;6(4):330343.

(15) Pourabdollahi Z, Karimi B, Mohammadian A. Joint model of freight mode and shipment size choice. Transportation Research Record. 2013;2378(1):84-91.

(16) Irannezhad E, Prato CG, Hickman M, Mohaymany AS. Copula-based joint discretecontinuous model of road vehicle type and shipment size. Transportation Research Record. 2017;2610(1):87-96.

(17) De Jong G, Ben-Akiva M. A micro-simulation model of shipment size and transport chain choice. Transportation Research Part B: Methodological. 2007;41(9):950-965.

(18) Zhao M, Chow JY, Ritchie SG. An inventory-based simulation model for annual-to-daily temporal freight assignment. Transportation Research Part E: Logistics and Transportation Review. 2015;79:83-101.

(19) Piendl R, Matteis T, Liedtke G. A machine learning approach for the operationalization of latent classes in a discrete shipment size choice model. Transportation Research Part E: Logistics and Transportation Review. 2019;121:149-161.

(20) Hesse M, Rodrigue JP. The transport geography of logistics and freight distribution. Journal of Transport Geography. 2004;12(3):171-184. 


\section{LIST OF TABLES}

TABLE 1 Sample size by commodity type and receiver function type

TABLE 2 Shipment size by commodity - receiver type category

TABLE 3 Summary statistics of independent variables (before log-transformation)

TABLE 4 Estimated coefficients of shipment size models (receiver function: office and factory)

TABLE 5 Estimated coefficients of shipment size models (receiver function: shop \& restaurant and logistics facility)

LIST OF FIGURES

FIGURE 1 Tokyo Metropolitan Area 
TABLE 1 Sample size by commodity type and receiver function type

\begin{tabular}{lrrrrr}
\hline & \multicolumn{2}{l}{$\begin{array}{l}\text { Receiver function } \\
\text { Office }\end{array}$} & Factory & $\begin{array}{l}\text { Shop \& } \\
\text { restaurant }\end{array}$ & \multicolumn{2}{l}{$\begin{array}{l}\text { Logistics } \\
\text { facility }\end{array}$} \\
\hline Agricultural products & & & 849 & 78 & 427 \\
Food products & 101 & 1,003 & 160 & 1,580 \\
Light manufacturing products & 587 & 2,744 & 107 & 1,102 \\
Wood and paper products & 341 & 347 & 26 & 364 \\
Minerals, ore, stone, cement, ceramics or glass & 124 & 610 & 32 & 83 \\
Metals or articles of metal & 368 & 3,616 & 21 & 317 \\
Machinery, appliances, and mechanical parts & 519 & 2,193 & 78 & 414 \\
Chemicals, rubber or plastics & 342 & 1,595 & 40 & 239 \\
\hline
\end{tabular}


TABLE 2 Shipment size by commodity - receiver type category

\begin{tabular}{|c|c|c|c|c|c|c|c|c|}
\hline \multirow[b]{2}{*}{ Commodity type } & $\begin{array}{l}\text { Mean (and } \\
\text { Receiver } \mathrm{f}\end{array}$ & SD) of ship & ment size in & & $\begin{array}{l}\text { One-wa } \\
\text { ANOV }\end{array}$ & & \multicolumn{2}{|c|}{$\begin{array}{l}\text { Kruskal-Wallis } \\
\text { Test }\end{array}$} \\
\hline & Office & Factory & $\begin{array}{l}\text { Shop \& } \\
\text { restaurant }\end{array}$ & $\begin{array}{l}\text { Logistics } \\
\text { facility }\end{array}$ & $\mathrm{F}$ & p-value & $\begin{array}{l}\text { chi- } \\
\text { squared }\end{array}$ & p-value \\
\hline $\begin{array}{l}\text { Agricultural } \\
\text { products }\end{array}$ & $\begin{array}{r}3,181 \\
(5,034)\end{array}$ & $\begin{array}{r}1,411 \\
(3,423)\end{array}$ & $\begin{array}{r}698 \\
(1,330)\end{array}$ & $\begin{array}{r}1,809 \\
(3,780)\end{array}$ & 9.43 & 0.000 & 81.1 & 0.000 \\
\hline Food products & $\begin{array}{r}1,090 \\
(2,614)\end{array}$ & $\begin{array}{r}1,256 \\
(2,517)\end{array}$ & $\begin{array}{r}226 \\
(697)\end{array}$ & $\begin{array}{r}2,297 \\
(3,531)\end{array}$ & 41.46 & 0.000 & 472.3 & 0.000 \\
\hline $\begin{array}{l}\text { Light } \\
\text { manufacturing } \\
\text { products }\end{array}$ & $\begin{array}{r}574 \\
(2,321)\end{array}$ & $\begin{array}{r}657 \\
(3,859)\end{array}$ & $\begin{array}{r}65 \\
(314)\end{array}$ & $\begin{array}{r}1,378 \\
(3,049)\end{array}$ & 14.25 & 0.000 & 512.4 & 0.000 \\
\hline $\begin{array}{l}\text { Wood and paper } \\
\text { products }\end{array}$ & $\begin{array}{r}674 \\
(1,693)\end{array}$ & $\begin{array}{r}1,078 \\
(2,524)\end{array}$ & $\begin{array}{r}1,708 \\
(6,804)\end{array}$ & $\begin{array}{r}1,558 \\
(2,995)\end{array}$ & 6.94 & 0.000 & 97.4 & 0.000 \\
\hline $\begin{array}{l}\text { Minerals, ore, } \\
\text { stone, cement, } \\
\text { ceramics or } \\
\text { glass }\end{array}$ & $\begin{array}{r}5,589 \\
(13,527)\end{array}$ & $\begin{array}{r}11,228 \\
(13,538)\end{array}$ & $\begin{array}{r}2,747 \\
(4,013)\end{array}$ & $\begin{array}{r}5,184 \\
(6,416)\end{array}$ & 13.73 & 0.000 & 121.4 & 0.000 \\
\hline $\begin{array}{l}\text { Metals or articles } \\
\text { of metal }\end{array}$ & $\begin{array}{r}1,157 \\
(2,639)\end{array}$ & $\begin{array}{r}1,677 \\
(4,486)\end{array}$ & $\begin{array}{r}1,282 \\
(2,726)\end{array}$ & $\begin{array}{r}3,144 \\
(7,940)\end{array}$ & 11.60 & 0.000 & 73.9 & 0.000 \\
\hline $\begin{array}{l}\text { Machinery, } \\
\text { appliances, and } \\
\text { mechanical } \\
\text { parts. }\end{array}$ & $\begin{array}{r}667 \\
(2,459)\end{array}$ & $\begin{array}{r}1,695 \\
(7,024)\end{array}$ & $\begin{array}{r}221 \\
(936)\end{array}$ & $\begin{array}{r}1,734 \\
(3,143)\end{array}$ & 5.49 & 0.001 & 212.1 & 0.000 \\
\hline $\begin{array}{l}\text { Chemicals, } \\
\text { rubber or } \\
\text { plastics }\end{array}$ & $\begin{array}{r}1,108 \\
(2,226)\end{array}$ & $\begin{array}{r}2,144 \\
(5,561)\end{array}$ & $\begin{array}{r}634 \\
(1,923)\end{array}$ & $\begin{array}{r}5,782 \\
(12,750)\end{array}$ & 28.96 & 0.000 & 134.4 & 0.000 \\
\hline
\end{tabular}


Sakai, Alho, Hyodo, and Ben-Akiva

TABLE 3 Summary statistics of independent variables (before log-transformation)

\begin{tabular}{lrrrr}
\hline Variable & \multicolumn{1}{c}{ Mean } & \multicolumn{1}{c}{ Median } & \multicolumn{1}{c}{ Min. } & \multicolumn{1}{c}{ Max. } \\
\hline Contract size (metric ton per annual) & 1040.6 & 69.4 & 0.0 & 89887.5 \\
Distance between supplier and receiver $(\mathrm{km})$ & 36.5 & 26.1 & 0.6 & 214.0 \\
Land price (mil. JPY per $\mathrm{m}^{2}$ ) & 0.167 & 0.092 & 0.005 & 12.126 \\
\hline
\end{tabular}




\section{TABLE 4 Estimated coefficients of shipment size models (receiver function: office and factory)}

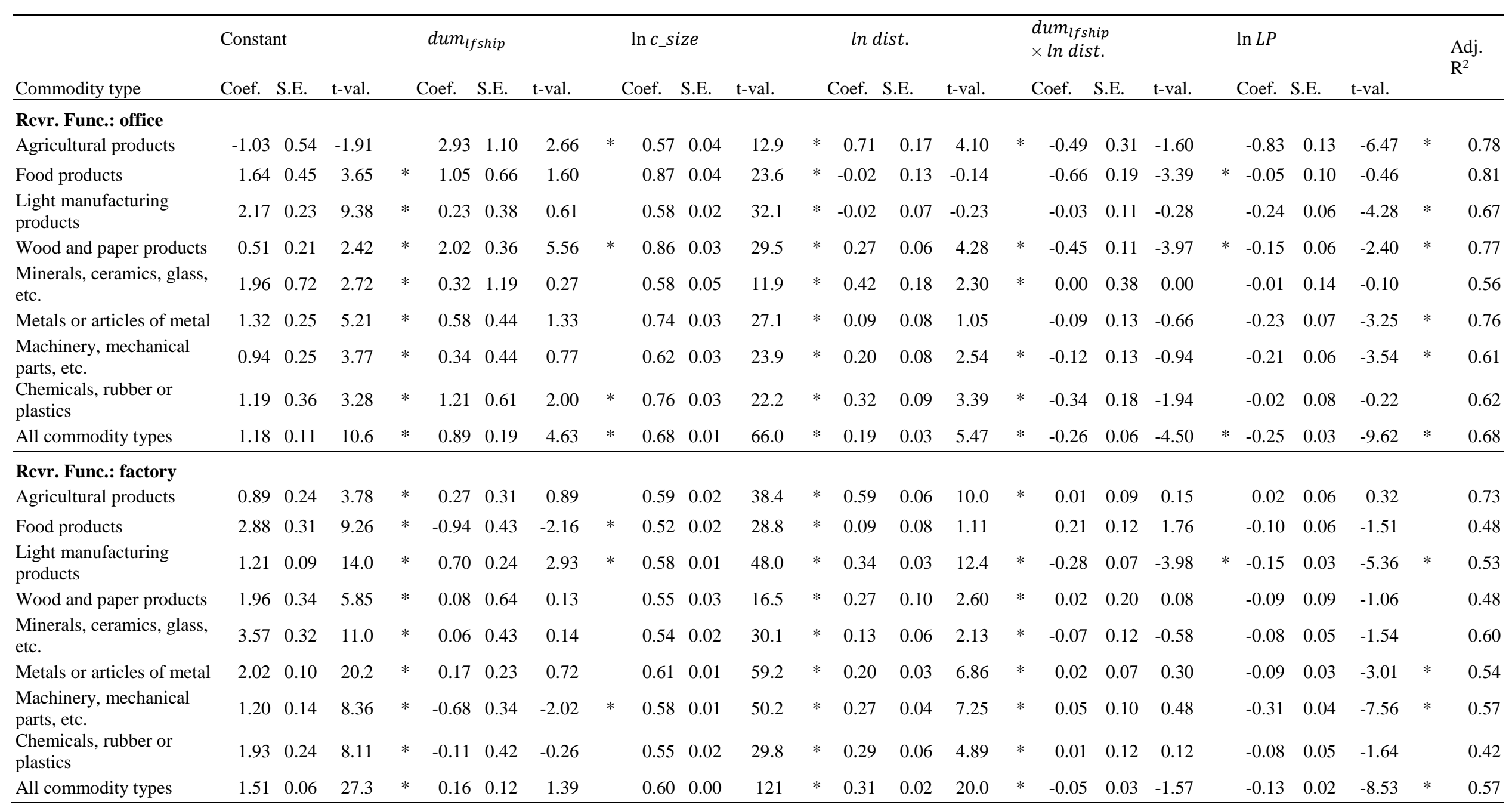

* Significant at a $95 \%$ confidence level (two-tailed) 
TABLE 5 Estimated coefficients of shipment size models (receiver function: shop \& restaurant and logistics facility)

\begin{tabular}{|c|c|c|c|c|c|c|c|c|c|c|c|c|c|c|c|c|c|c|c|c|c|c|c|c|c|}
\hline \multirow[b]{2}{*}{ Commodity type } & \multicolumn{3}{|c|}{ Constant } & \multicolumn{4}{|c|}{$d u m_{l f s h i p}$} & \multicolumn{4}{|c|}{$\ln c_{-}$size } & \multicolumn{3}{|c|}{ ln dist. } & \multirow[b]{2}{*}{$\mathrm{t}$-val. } & \multicolumn{3}{|c|}{$\begin{array}{l}\text { dum }_{\text {lfship }} \\
\times \text { ln dist. }\end{array}$} & \multirow[b]{2}{*}{$\mathrm{t}$-val. } & \multicolumn{3}{|c|}{$\ln L P$} & \multirow[b]{2}{*}{$\mathrm{t}$-val. } & & \multirow{2}{*}{$\begin{array}{l}\text { Adj. } \\
\mathrm{R}^{2}\end{array}$} \\
\hline & Coef. & S.E. & $\mathrm{t}$-val. & & Coef. & S.E. & t-val. & & Coef. & S.E. & $\mathrm{t}$-val. & & Coef. & S.E. & & & Coef. & S.E. & & & Coef. & S.E. & & & \\
\hline \multicolumn{26}{|c|}{ Revr. Func.: shop \& restaurant } \\
\hline Agricultural products & 0.55 & 0.49 & 1.11 & & 0.41 & 0.69 & 0.59 & & 0.90 & 0.06 & 13.9 & $*$ & 0.54 & 0.18 & 3.03 & $*$ & -0.48 & 0.25 & -1.90 & & 0.03 & 0.12 & 0.24 & & 0.80 \\
\hline Food products & 1.77 & 0.29 & 6.03 & $*$ & -0.12 & 0.44 & -0.27 & & 0.84 & 0.04 & 22.9 & * & -0.07 & 0.10 & -0.74 & & 0.12 & 0.15 & 0.77 & & 0.10 & 0.07 & 1.39 & & 0.81 \\
\hline Light manufacturing products & 1.68 & 0.21 & 7.89 & $*$ & -0.80 & 0.80 & -1.01 & & 0.81 & 0.06 & 14.3 & $*$ & -0.35 & 0.11 & -3.26 & $*$ & 0.76 & 0.26 & 2.87 & $*$ & -0.10 & 0.08 & -1.30 & & 0.71 \\
\hline Five commodity types a) & 1.76 & 0.62 & 2.85 & $*$ & 1.01 & 0.77 & 1.31 & & 0.58 & 0.05 & 12.0 & $*$ & 0.09 & 0.17 & 0.54 & & -0.45 & 0.23 & -1.96 & & -0.32 & 0.14 & -2.29 & $*$ & 0.48 \\
\hline All commodity types & 1.19 & 0.20 & 6.07 & $*$ & 0.62 & 0.33 & 1.86 & & 0.74 & 0.03 & 29.1 & $*$ & 0.18 & 0.07 & 2.41 & * & -0.22 & 0.11 & -2.05 & * & -0.08 & 0.06 & -1.50 & & 0.65 \\
\hline \multicolumn{26}{|l|}{ Revr. Func.: logistics facility } \\
\hline Agricultural products & 1.57 & 0.37 & 4.26 & $*$ & 2.18 & 0.52 & 4.22 & * & 0.41 & 0.04 & 9.75 & $*$ & 0.58 & 0.09 & 6.57 & $*$ & -0.21 & 0.15 & -1.46 & & & & & & 0.42 \\
\hline Food products & 2.56 & 0.25 & 10.1 & $*$ & 0.37 & 0.31 & 1.22 & & 0.51 & 0.02 & 22.8 & * & 0.23 & 0.06 & 4.02 & $*$ & 0.03 & 0.09 & 0.34 & & & & & & 0.29 \\
\hline Light manufacturing products & 1.60 & 0.28 & 5.61 & $*$ & 0.57 & 0.34 & 1.70 & & 0.65 & 0.02 & 30.2 & * & 0.38 & 0.07 & 5.15 & * & -0.08 & 0.10 & -0.79 & & & & & & 0.46 \\
\hline Wood and paper products & 4.27 & 0.36 & 11.8 & $*$ & 0.32 & 0.45 & 0.72 & & 0.32 & 0.03 & 11.4 & * & -0.08 & 0.11 & -0.67 & & 0.18 & 0.15 & 1.22 & & & & & & 0.30 \\
\hline Minerals, ceramics, glass, etc. & 3.60 & 0.66 & 5.43 & $*$ & -2.18 & 0.69 & -3.14 & * & 0.55 & 0.05 & 10.6 & $*$ & 0.10 & 0.16 & 0.65 & & 0.63 & 0.21 & 3.04 & $*$ & & & & & 0.74 \\
\hline Metals or articles of metal & 0.45 & 0.42 & 1.08 & & 0.80 & 0.48 & 1.65 & & 0.86 & 0.04 & 23.6 & * & 0.33 & 0.10 & 3.19 & $*$ & -0.21 & 0.14 & -1.50 & & & & & & 0.67 \\
\hline $\begin{array}{l}\text { Machinery, mechanical parts, } \\
\text { etc. }\end{array}$ & 3.05 & 0.38 & 8.13 & $*$ & 1.10 & 0.56 & 1.97 & & 0.66 & 0.03 & 21.6 & $*$ & 0.08 & 0.11 & 0.74 & & -0.58 & 0.16 & -3.62 & $*$ & & & & & 0.57 \\
\hline Chemicals, rubber or plastics & 4.29 & 0.45 & 9.49 & $*$ & -1.09 & 0.84 & -1.31 & & 0.51 & 0.04 & 13.5 & * & 0.03 & 0.11 & 0.30 & & 0.20 & 0.24 & 0.83 & & & & & & 0.44 \\
\hline All commodity types & 2.57 & 0.12 & 20.6 & $*$ & 0.34 & 0.16 & 2.08 & * & 0.56 & 0.01 & 56.2 & * & 0.20 & 0.03 & 6.08 & * & -0.01 & 0.05 & -0.31 & & & & & & 0.42 \\
\hline
\end{tabular}

* Significant at a $95 \%$ confidence level (two-tailed)

Note: a) Five commodity types ("wood and paper products", "minerals, ceramics, glass, etc.", "metals or articles of metal", "machinery, mechanical parts, etc.", and "chemicals, rubber or plastics") are merged as the sample size for each of the five types is too small to estimate models independently. 


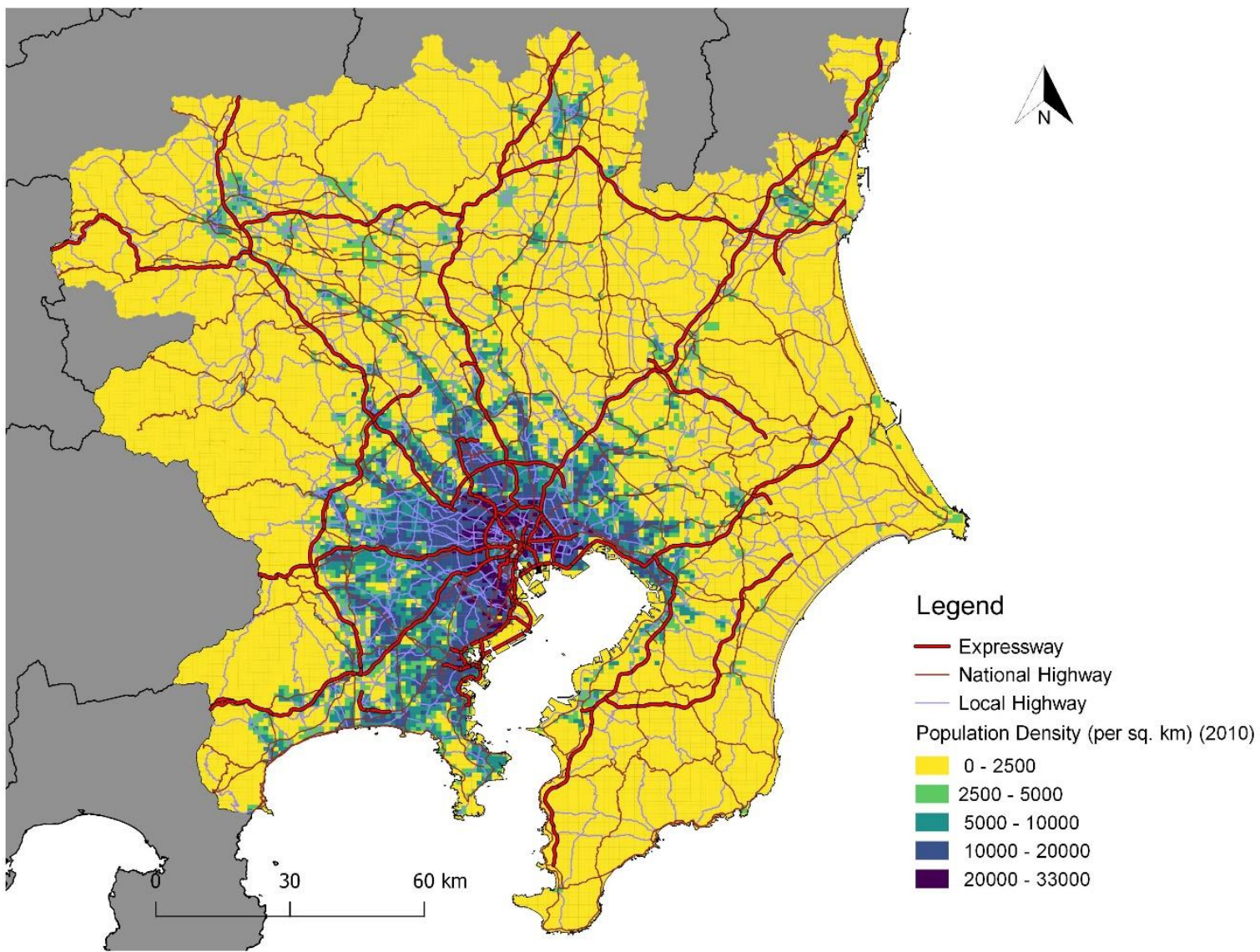

FIGURE 1 Tokyo Metropolitan Area 